\title{
Insulin effects on beta and theta activity in the human brain are differentially affected by ageing
}

\author{
O. Tschritter • A. M. Hennige • H. Preissl • \\ Y. Grichisch • K. Kirchhoff • K. Kantartzis • \\ F. Machicao • A. Fritsche $\cdot$ H.-U. Häring
}

Received: 3 July 2008 / Accepted: 26 September 2008 / Published online: 19 November 2008

(C) Springer-Verlag 2008

Keywords Central nervous system $\cdot$ CNS .

Insulin resistance $\cdot$ Magnetoencephalography $\cdot$ MEG .

Type 2 diabetes mellitus

\section{Abbreviation \\ MEG magnetoencephalography}

To the Editor: In peripheral tissues glucose uptake is established as a measure of insulin sensitivity, whereas the majority of glucose fluxes into the brain are insulin independent. However, at the level of neurons within the brain, insulin has been shown to modulate cell cycle, neurotransmitter production and electrical activity, and when insulin action fails, alterations in neuronal survival, food intake, body weight and determination of life-span occur. Based on these findings, insulin resistance of the brain is proposed to contribute to the development of obesity [1].

O. Tschritter · A. M. Hennige $\cdot$ Y. Grichisch $\cdot$ K. Kirchhoff $\cdot$ K. Kantartzis $\cdot$ F. Machicao $\cdot$ A. Fritsche $\cdot$ H.-U. Häring $(\bowtie)$ Department of Internal Medicine IV, University of Tübingen, Otfried-Müller-Straße 10,

72076 Tübingen, Germany

e-mail: hans-ulrich.haering@med.uni-tuebingen.de

H. Preissl

Institute of Medical Psychology and Behavioural Neurobiology, University of Tübingen,

Tübingen, Germany

H. Preissl

Department of Obstetrics and Gynecology, College of Medicine, University of Arkansas for Medical Sciences,

Little Rock, AR, USA
While peripheral insulin sensitivity is elevated in lean individuals, an increase in body weight impairs insulininduced glucose uptake into peripheral tissues in obese individuals, and there is a strong correlation between insulin sensitivity and ageing in various animal models and humans. It should be noted that this correlation is largely dependent on an increase in body weight and alterations in body composition rather than age [2]. Therefore, although insulin sensitivity in peripheral tissues certainly decreases in ageing individuals, it is highly likely that age is not a strong independent predictor of peripheral insulin sensitivity.

Based on these data, the aim of the present study was to investigate whether the effects of insulin on distinct brain activation patterns are associated with age, independent of obesity and body fat mass, by using magnetoencephalography (MEG) measurements [3] to detect insulin-dependent alterations in cerebrocortical activity in humans. Cerebrocortical beta and theta activity was measured by MEG in 50 participants (26 men, 24 women; age 34 2 [20-61] years; BMI $27 \pm 1$ [17-36] $\mathrm{kg} / \mathrm{m}^{2}$; mean $\pm \mathrm{SE}$ [range]) during a two-step euglycaemic-hyperinsulinaemic clamp [3]. All individuals took part in a saline experiment, and MEG data from the saline experiment were subtracted from the insulin experiment to eliminate non-insulin-derived variations. The study protocol was approved by the Ethics Committee of the University of Tübingen and all participants gave written informed consent prior to the study. To control for covariates, we used a multiple regression model with age, sex and BMI as independent variables.

As expected, the multiple regression analysis revealed a significant negative correlation between peripheral insulin sensitivity and BMI ( $r=-0.64, p<0.001$, Fig. 1b), but displayed no independent correlation with age $(p=0.15$, 
Fig. 1a). In parallel, the insulin effect on theta activity was negatively correlated with BMI $(r=-0.33, p=0.022$, Fig. 1d) but not with age ( $p=0.22$, Fig. $1 \mathrm{c})$. By contrast, the effect of insulin on cerebrocortical beta activity was negatively correlated with age $(r=-0.41, p=0.004$, Fig. 1e), while BMI had no effect ( $p=0.26$, Fig. 1f). These findings clearly implicate a specific age-related decline in beta activity measured by MEG, while peripheral insulin sensitivity and theta activity mainly depend on alterations that are associated with obesity in ageing individuals.

Mechanistically, obesity leads to alterations in adipokine, NEFA and cytokine levels to cause peripheral insulin resistance. However, it is unknown whether such mechanisms are relevant to impaired insulin action in the brain or whether insulin resistance in the brain per se leads to obesity, which is followed by metabolic disturbances [4]. To verify that the measures of cerebral insulin sensitivity are not a direct function of peripheral insulin sensitivity, we also performed correlation and multiple regression analyses using the data on peripheral insulin sensitivity. Beta and theta activity were correlated with peripheral insulin sensitivity, but the multiple regression analyses revealed that these correlations were no longer statistically signifi- cant after adjusting for BMI and age (theta activity $p=0.16$, beta activity $p=0.23$ ). Therefore, the nature of cerebral and peripheral insulin resistance seems to be diverse. Further support for the hypothesis that cerebral insulin resistance is a pathogenic factor of obesity is provided by the fact that a reduction in theta activity has been associated with the loss of locomotor activity and voluntary movement in rodents [5], and that obese mice that are physically inactive show diminished cortical activity, with the greatest reductions seen in the theta frequency spectrum (A. M. Hennige, unpublished data).

While it is unclear whether increased theta activity is a cause or effect of increased BMI, the loss of insulinmediated beta activity clearly suggests that ageing reduces insulin sensitivity in the brain. In this line, the underlying mechanisms and the functional consequences of altered beta activity and the finding that insulin sensitivity in the beta band displayed no significant correlation with BMI after adjusting for age is difficult to interpret. One may speculate that insulin-induced beta activity is only partially responsible for body weight regulation and, rather, represents an age-related decline in insulin effects on other brain functions, such as memory function $[6,7]$ and cognition in a

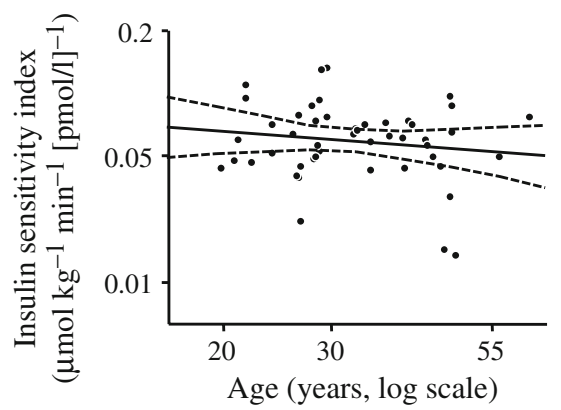

b

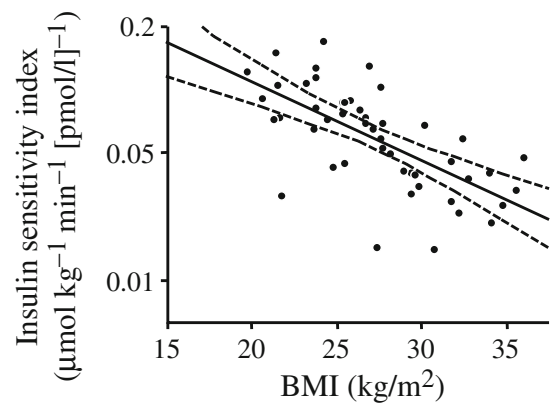

C

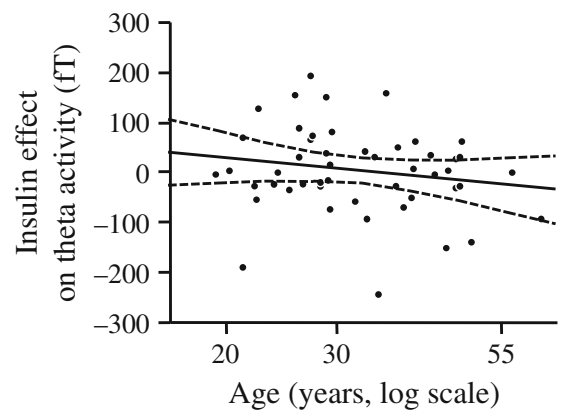

d

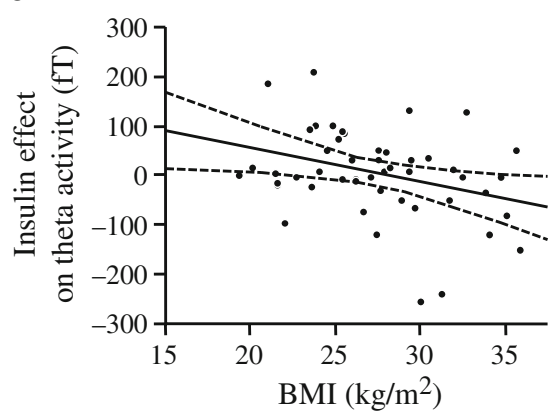

e

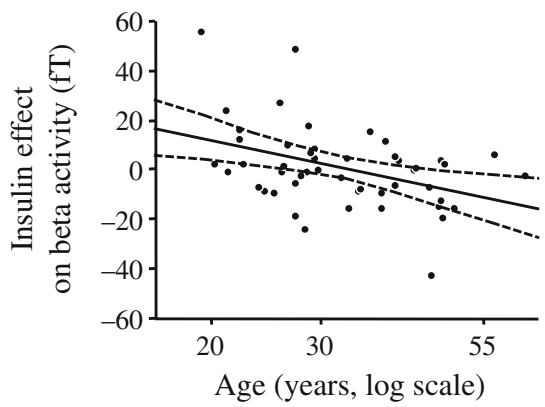

$\mathbf{f}$

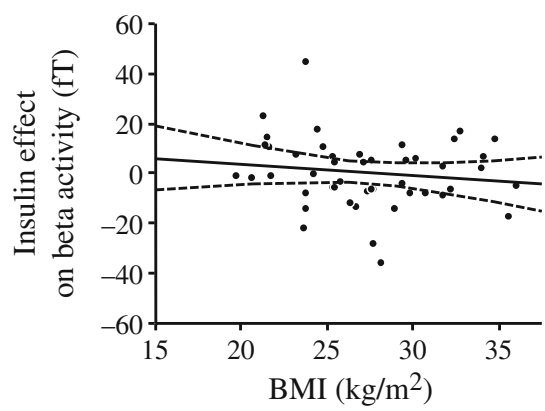

Fig. 1 Correlations of different measures of insulin sensitivity with age and BMI in multiple regression analyses including sex, age and $\mathrm{BMI}$ as independent variables. Peripheral insulin sensitivity $(\mathbf{a}, \mathbf{b})$ was negatively correlated with BMI $(r=0.64, p<0.001)$, but was not correlated with age $(p=0.15)$. This indicates that BMI is an independent predictor of peripheral insulin sensitivity, whereas age is not. Similarly, the effect of insulin on theta activity (c, d) was significantly correlated with BMI $(r=0.33, p=0.022)$, whereas age had no independent effect $(p=0.22)$. In contrast, the insulin effect on beta activity (e, f) was negatively correlated with age $(r=0.41, p=0.004)$, whereas BMI had no effect independently from age and sex $(p=0.26)$. The solid line represents the slope of the regression and the dotted lines indicate the $95 \% \mathrm{CI}$ for the slope 
Alzheimer's disease [8]. However, we have previously published data that support a role for beta activity in energy homeostasis, showing that insulin-mediated beta activity is diminished in body-weight-matched carriers of the risk allele in FTO [9], and food intake is increased [10]. In addition, insulin sensitivity in beta activity might be influenced to a larger degree by ongoing processing related to behavioural aspects. Although behaviour reflected by insulin-induced changes in beta activity may be relevant to the development of obesity, a chronic measure such as BMI is possibly not an ideal variable to be included in the multiple regression analysis. This hypothesis is further supported by the fact that beta activity is mainly generated in the cerebral cortex itself and is characteristically involved in attention and processes that integrate external information [11], while theta activity is largely influenced by subcortical areas such as the hippocampus [12].

In conclusion, our data suggest that modulation of beta and theta activity represents measures of insulin resistance in the brain that are differently regulated. While insulin sensitivity in beta activity declined with age, insulindependent theta activity showed a close association with obesity. Although speculative, theta activity may represent regulation of locomotor activity by insulin, while beta activity represents cognitive functions that do not necessarily reflect body weight.

Acknowledgements We gratefully acknowledge the superb technical assistance of A. Teigeler, H. Luz and G. Walker. This study was supported by the Deutsche Forschungsgemeinschaft (KFO 114) and a Fortüne grant of the University of Tübingen.

Duality of interest statement The authors declare that there is no duality of interest associated with this manuscript.

\section{References}

1. Gerozissis K (2008) Brain insulin, energy and glucose homeostasis; genes, environment and metabolic pathologies. Eur J Pharmacol 585:38-49

2. Ferrannini E, Vichi S, Beck Nielsen H, Laakso M, Paolisso G, Smith U (1996) Insulin action and age. European Group for the Study of Insulin Resistance (EGIR). Diabetes 45:947-953

3. Tschritter O, Preissl H, Hennige AM et al (2006) The cerebrocortical response to hyperinsulinemia is reduced in overweight humans: a magnetoencephalographic study. Proc Natl Acad Sci USA 103:12103-12108

4. Bruning JC, Gautam D, Burks DJ et al (2000) Role of brain insulin receptor in control of body weight and reproduction. Science 289:2122-2125

5. Dzoljic E, van Leeuwen R, de Vries R, Dzoljic MR (1997) Vigilance and EEG power in rats: effects of potent inhibitors of the neuronal nitric oxide synthase. Naunyn Schmiedebergs Arch Pharmacol 356:56-61

6. Benedict C, Hallschmid M, Hatke A et al (2004) Intranasal insulin improves memory in humans. Psychoneuroendocrinology 29:1326-1334

7. Hallschmid M, Benedict C, Schultes B, Born J, Kern W (2008) Obese men respond to cognitive but not to catabolic brain insulin signaling. Int J Obes (Lond) 32:275-282

8. Reger MA, Watson GS, Green PS et al (2008) Intranasal insulin improves cognition and modulates beta-amyloid in early $\mathrm{AD}$. Neurology 70:440-448

9. Tschritter O, Preissl H, Yokoyama Y, Machicao F, Haring HU, Fritsche A (2007) Variation in the FTO gene locus is associated with cerebrocortical insulin resistance in humans. Diabetologia 50:2602-2603

10. Speakman JR, Rance KA, Johnstone AM (2008) Polymorphisms of the FTO gene are associated with variation in energy intake, but not energy expenditure. Obesity (Silver Spring) 16: 1961-1965

11. Laufs H, Krakow K, Sterzer P et al (2003) Electroencephalographic signatures of attentional and cognitive default modes in spontaneous brain activity fluctuations at rest. Proc Natl Acad Sci USA 100:11053-11058

12. Tesche CD, Karhu J (2000) Theta oscillations index human hippocampal activation during a working memory task. Proc Natl Acad Sci USA 97:919-924 